\title{
La agricultura como forma de resistencia campesina ${ }^{*}$
}

\author{
Sandra Chancay
}

\begin{abstract}
RESUMEN
En los años 90, las familias campesinas del Cantón Paján, al sur de la provincia de Manabí, abandonaron SUS COMUNIDAdES LUEGO DE UNA PROFUNDA CRISIS DE PRODUCCIÓN Y CONSECUENTE CAÍdA DEL PRECIO DEL CAFÉ, PRINCIPAL PRODUCTO DE LA ZONA. LAS FAMILIAS QUE SE QUEDARON PUSIERON EN FUNCIONAMIENTO UNA SERIE DE ESTRATEGIAS DE RESISTENCIA Y PRÁCTICAS DE DIVERSIFICACIÓN DE LA PRODUCCIÓN, ENTRE LAS QUE SE ENCUENTRA EL CAFÉ. La inVestigación privilegió el trabajo en tres comunidades: San Francisco, La Trinidad y Mocoral, QUe SE fORMARON CON El AUge CAFETERo. ENTRE El 2002 y El 2009 las Visitas de CAMPO, ENTREVISTAS Y ENCUESTAS PERMITIERON OBTENER DATOS MÁS PRECISOS SOBRE LA PRODUCCIÓN DE CAFÉ, DESDE LA ÉPOCA DE BONANZA EN los años 90 hasta su Caída a finales de la misma década. SE PRIVILEgió una Metodología Cualitativa QUE ARTICULA HISTORIAS DE VIDA, CON ENTREVISTAS EN PROFUNDIDAd Y ANÁlisis de FUENTES DOCUMENTALES Y ESTADÍSTICAS PARA PRESENTAR LA FORMA DE HACER AGRICULTURA EN LA ZONA, LA IMPORTANCIA DEL CAFÉ Y LAS ESTRATEGIAS FAMILIARES DE RESISTENCIA.
\end{abstract}

Palabras clave: Paján - familias Campesinas - Resistencia - diversificación - Café - ProducCión.

Abstract

In the nineties the Campesina families from Puján County, in the South of the Manabí Province, ABandoned THEIR COMMUNITIES AFTER A DEEP CRISIS OF PRODUCTIVITY PAIRED WITH A DROP IN THE PRICE OF COFFEE, THE MAIN PRODUCT IN THE ZONE. THE FAMILIES WHO STAYED INITIATED A SET OF SURVIVAL STRATEGIES AND PRODUCTION DIVERSIFICATION PRACTICES, INCLUdING COFFEe. THE RESEARCH FOCUSED FIELDWORK IN THREE COMMUNITIES: SAN Francisco, La Trinidad and Mocoral, which were founded during the coffee boom. Between 2002 and 2009 FIELDWORK, INTERVIEWS AND SURVEYS PRODUCED MORE PRECISE INFORMATION ABOUT COFFEE PRODUCTION FROM ITS BOOM IN THE NINETIES TO ITS FALL AT THE END OF THE SAME DECADE. QUALITATIVE METHODOLOGY THAT COMBINES LIFE STORIES, IN-DEPTH INTERVIEWS AND ANALYSIS OF BIBLIOGRAPHICAL AND STATISTICAL SOURCES PRESENTS THE STYLE OF AGRICULTURE IN THE AREA, THE IMPORTANCE OF COFFEE, AND COMMON RESISTANCE STRATEGIES.

Keywords: Paján - Peasant families - Resistance - diversification - COFFEe Production.

* Este artículo es parte de la disertación previa a la obtención del título de Licenciada en Antropología, La agricultura campesina en Paján. 1990-2009, presentada en la Escuela de Antropología del Departamento de Ciencias Humanas en la Pontificia Universidad Católica del Ecuador en el año 2015.

**Antropóloga por la Pontificia Universidad Católica del Ecuador. Correo electrónico: sandrachancay4@hotmail.com. 


\section{Introducción}

Daján, en la zona sur de la provincia de Manabí, era parte del territorio de las comunas libres en la época colonial. Hasta entrados los años 30 del siglo anterior de sus montañas se extraían tagua y café para la exportación y productos agrícolas para el mercado interno, con una forma de producción que permitía combinar la atención de las demandas externas del mercado con la reproducción de la vida campesina.

En Manabí, a partir de 1930 las pequeñas unidades de producción tipo finca (Ferrín, 1989) se dedicaron a la producción de café y fue en las zonas montañosas de Jipijapa y Paján donde la superficie cafetalera y la productividad alcanzó niveles altos debido al auge de las exportaciones de café (Guerrero, 2013). En la década de los años 90 el cultivo del café entró en crisis por la caída de los precios en el mercado internacional, la presencia de plagas, períodos de sequía y presencia del fenómeno El Niño que afectó profundamente la economía de las familias campesinas.

La crisis de la caficultura de finales del siglo pasado y en general de la agricultura, el creciente desarrollo industrial de la ciudad de Guayaquil que demandaba mano de obra para atender las necesidades de modernización, así como las condiciones de producción de las fincas campesinas, hicieron que la mayoría de los habitantes decida migrar, convirtiendo a muchas comunidades del sur de Manabí, y de Paján en particular, en pueblos "fantasmas".

La investigación realizada se centró en los mecanismos implementados por las familias para mantenerse en el campo, en este artículo se describen las estrategias que pusieron en funcionamiento las familias para afrontar esos largos años de crisis con una forma de hacer agricultura que privilegia la tierra y los recursos naturales.

\section{Descripción de la zona}

El cantón Paján se ubica al extremo sur de la provincia de Manabí en la costa de Ecuador, en el límite con la provincia de Guayas. Tiene una superficie aproximada de 1.081,1 kilómetros cuadrados (AME, 2014), con zonas montañosas de bosque húmedo y bosque seco tropical que son la prolongación oriental de las montañas de Colonche y Chongón. Las pendientes son numerosas con cumbres planas y alargadas a los que les denominan "tabladas". Se pueden distinguir dos zonas: una de laderas y pendientes más húmeda cuyas alturas no sobrepasan los 600 m.s.n.m. y otra más seca con terrenos planos. "Ubicada a poca distancia del litoral, la zona se beneficia con la garúa, por estar más cerca del mar y tener una mayor altitud. Allí, esta humedad atmosférica parece atenuar en cierta medida la falta de lluvia en el verano y en los inviernos deficitarios" (Dubly, 1984: 110).

La temperatura promedio es de 24 grados centígrados y una precipitación media anual entre 1.000 y 2.000 m.m. (Plúas, 2011: 73). Como toda la provincia de Manabí, este cantón no recibe el agua de los deshielos de la Cordillera de los Andes; el agua para riego proviene del río Paján que nace en sus montañas y para el consumo las familias se abastecen de innumerables pozos y esteros pues no disponen o no tienen acceso a agua potable.

El Plan Integral de Desarrollo de los Recursos Hídricos de la Provincia de Manabí (1989) planeó construir el Proyecto de Propósito Múltiple Paján / Misbaque, un embalse para abastecer de agua de riego y agua potable a los cantones de Paján, Jipijapa y Puerto López. Más de 400 familias fueron desplazadas para la construcción del embalse pero en el fenómeno de El Niño de 1997 la Presa Paján se azolvó y no se pudo concluir la obra por lo que esos terrenos se aprovechan para la agricultura de productos de ciclo corto.

Según los datos del Censo 2010, la población total del cantón es de 37.073 habitantes, de los cuales el 83.1\%, es decir 29.892 personas viven en las áreas rurales ocupada en actividades de agricultura y ganadería lo que da cuenta de la orientación eminentemente agropecuaria de sus zonas rurales. 
Paján tiene uno de los más altos índices de necesidades básicas insatisfechas en la provincia con el 94.5\%, muy por encima de los niveles de NBI del resto del país (SNI, 2010). La tasa de analfabetismo en el cantón llega al $21.5 \%$, en el área rural es de $23.2 \%$ y el de las mujeres alcanza el 25.1\%; el promedio de años aprobados de educación para el área rural es de apenas el 3.5. Solo el 19.4\% tiene acceso a red de agua pública, el $38.4 \%$ tiene acceso a agua de pozo, el $38.3 \%$ acceso a agua de vertiente y el $67.5 \%$ de las viviendas tiene acceso a luz eléctrica. (INEC, 2014).

El 19.2\% de la población de Manabí se autoidentifica como montubia y en Paján el 49.38\% se reconocen a sí mismas como montubias, los apellidos de las familias son apellidos aborígenes: Choez, Baque, Parrales, Pilay; y, típicamente manabitas: Pincay, Toala, Lino (Dubly, 1984: 122).

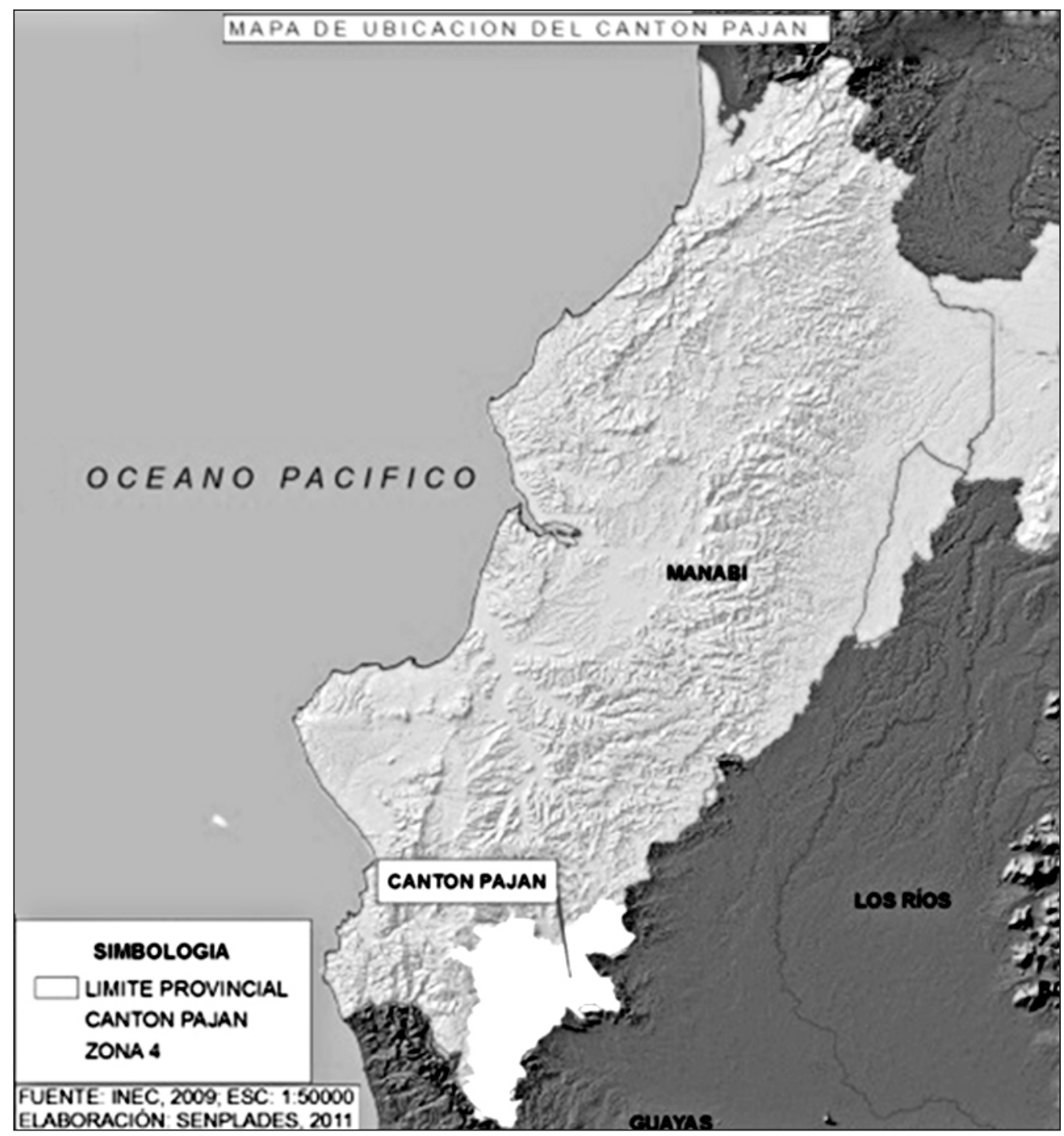

MAPA 1. Ubicación del cantón Paján. Fuente: Sistema Nacional de Información. 2011 


\section{Un poco de historia de la agricultura campesina en la zona sur de Manabí}

Los cronistas españoles dan cuenta de la antigüedad del poblamiento de sus territorios y la riqueza de los productos (Dueñas, 1986: 7). Describieron un tipo de agricultura de roza y quema, es decir que se desbrozaba un claro y con herramientas sencillas se sembraba, obteniendo abundantes rendimientos de maíz, yuca, camote, a lo que se sumaba la caza y la pesca y actividades de comercio e intercambio con el sur en Perú y el norte hasta México (Ibíd.: 21-27).

Una vez implantado el régimen colonial, las autoridades se encuentran con una población devastada por la conquista y poco acostumbrada a rendir prestaciones en trabajo o en tributo, y la escasez crónica de fuerza de trabajo pues muchos de sus habitantes preferían internarse en los bosque que someterse a autoridad alguna. (Ibíd.: 28). Las nuevas autoridades españolas debieron ejercer un efectivo control sobre la fuerza de trabajo indígena, para lo cual se valieron de las autoridades étnicas tradicionales para el trabajo en encomiendas y el pago de tributos. (Ibíd.)

En 1763 cuando Jipijapa es elevada al rango de parroquia, Paján ya existía y el resto de poblados se va conformando por desmembración en provecho de territorios vecinos rivales (Dubly, 1984: 120). Según las referencias de Dueñas (1991), los terrenos de Paján se describen como "inaccesibles y fragosos", sin embargo los indios reclamaban título de propiedad para estas tierras, así en la "Compulsa de los Indios de Jipijapa para obtener título de propiedad" y en la "Correspondencia del Gobernador de Manabí con el Ministro del Interior, Año de 1853" se relata:

"Los indios solicitaban título de propiedad y amparo sobre un vasto territorio, comprendido entre el río Ayampe y las montañas de Paján al sur, Chial y Lodana al este, el Océano Pacífico al oeste, y al norte de la ensenada del Cayo, las tierras de comunidad de los indios de Montecristi. La extensión de este territorio, que en la actualidad corresponde a los Cantones de Jipijapa, Paján y 24 de Mayo, puede estimarse en aproximadamente 4.000 km2" (Ibíd.: 37).

La disputa por la tenencia de la tierra no termina durante las guerras de Independencia, no obstante las dificultades e insubordinación con respecto al cobro de tributos en la zona de Jipijapa y Montecristi durante la época colonial. Los indios volvieron a aceptar el tributo en 1838 a pesar de que se había suprimido en Manabí en 1826, cediendo el territorio étnico y reteniendo el derecho comunitario a la tierra (Ibíd., 1987).

Esta forma de tenencia de la tierra de manera comunitaria luego de 1860 , cede paso a la ocupación de las tierras para los cultivos de caucho y tagua, y la actividad artesanal de sombreros de paja toquilla, que en los primeros años de la República permitió una incorporación al mercado internacional y generó un proceso de apropiación privada a través de la constitución de haciendas dedicadas a la agricultura y ganadería (Ibíd., 1991).

La confección de sombreros de paja toquilla se la hacía a partir de la recolección y secado de una palma, Carludovica Palmataque, que crecía en estado silvestre en la montaña costeña. Entre 1823 y 1862 se llegaron a exportar por Manta y Guayaquil 1.705.029 sombreros, sin contar los que salían por los puertos no autorizados.

El tejido del sombrero de paja toquilla es la actividad más importante del siglo XIX en la zona del sur de Manabí, favorecida por la cercanía a los centros de producción de la fibra y a la presencia de población indígena dedicada a esta labor artesanal donde se producía en mayor escala. A fines del siglo XIX decae la exportación y se inicia la de otros productos silvestres como la tagua, el caucho y más adelante el cacao, que significó la extensión de la frontera agrícola en detrimento de los bosques del interior de la provincia (Ibíd., 1986: 65-67).

Hacia 1915, con la caída de las exportaciones por la presencia de plagas que afectaron la producción cacaotera (escoba de bruja y monilla), se redujo drásticamente la superficie 
sembrada y por consiguiente el volumen exportado. Entre 1925 y 1938, una alternativa para los hacendados fue vender una parte de las tierras para solventar las deudas o la otra darla en arriendo (Ibíd., 1991).

El incremento del comercio mundial que demandaba materias primas hizo que nuevos territorios se fueran incorporando a los cantones de Manabí así como nuevas zonas productivas con la formación de estancias en las que había ganado y cultivos. Esta situación se vio favorecida con el auge de la producción agrícola, el incremento de la población y la conformación de nuevos poblados (Zambrano, 2007: 44). Esta actividad no estuvo exenta de conflictos, la población originaria reclamaba las tierras que les habían sido expropiadas y rechazaban el cobro de tributos.

Las relaciones de las familias campesinas con la hacienda cacaotera y con el capital agroexportador hicieron que la entrada del capitalismo en el campo manabita adquiera características específicas. El capitalismo se desarrolla en función de la actividad primarioexportadora en donde los campesinos son los que corren riesgos en la fase de producción (cultivo y recolección) de las materias primas, y los que sufren la inestabilidad de los precios del mercado mundial.

Ha sido precisamente este finquero el que ha ido buscando nuevas zonas para incursionar en la agricultura por ello luego de la caída de los precios del cacao deviene en la segunda mitad del siglo XX el cultivo del café.

"El móvil de la migración ha sido sin duda alguna, en la gran mayoría de los casos, la búsqueda de tierra de montaña libre de ocupantes, y húmeda. La presión demográfica relativa y la sequía empujaron hacia adentro a los moradores de la franja litoral de ocupación antigua y con pocas lluvias (principalmente desde Jipijapa y Julcuy, quizás también Machalilla), la cual se despobló progresivamente en provecho de las áreas de montaña y otros lugares del país" (Dubly, 1984:122).

La ocupación de los nuevos territorios para destinarlos al cultivo del café aprovechó las escasas precipitaciones y la humedad del suelo. Las familias campesinas se enfrentan de esta manera, a la incertidumbre de la disponibilidad hídrica, a la cercanía o aislamiento de vías de comunicación para sacar los productos, a la constante división de sus tierras por herencia, lo que da como consecuencia procesos de diferenciación socioeconómica de las familias campesinas (Ibíd., 1984).

Con la bonanza del café en los años 70 y 80 mucha gente llegó desde otras zonas de la provincia a las montañas de Paján. La historia de la tenencia de la tierra, la forma de hacer agricultura y la de los campesinos está marcada por esta relación con el mercado.

"El acceso a la tierra en Manabí ha estado determinado históricamente por la presencia hegemónica de la actividad comercial exportadora, a cuyos avatares ha estado vinculada la orientación general de la economía provincial y, por tanto, la valorización de las actividades productivas agrícolas y la transformación de la relación con la tierra" (Ferrín, 1989: 112).

Esta autora distingue tres fases en la constitución de la propiedad territorial en Manabí que son al mismo tiempo referentes de la relación de los campesinos con la tierra:

“... una primera fase de (1800-1860), la explotación de la tierra se hacía bajo formas comunitarias y de libre usufructo en tanto la actividad productiva hegemónica constituía la manufactura del sombrero de paja toquilla y su exportación"; [una] "segunda fase (1860-1930), la actividad comercial exportadora se sustenta en la provisión de materias primas de origen vegetal, fundamentalmente tagua, caucho, cacao y café, con lo cual se genera un acelerado y violento proceso de apropiación privada y monopolización de la tierra." [La] "tercera fase (1930 en adelante), se caracteriza por la crisis de la gran propiedad y el florecimiento de unidades de producción tipo finca, la actividad productiva hegemónica es la producción del café con destino al mercado mundial" (Ibíd.: 112-114). 
La producción extraída de las fincas permitió a las familias campesinas vincularse al mercado y a las demandas de la sociedad, a cambio de lo cual recibían una parte de lo que necesitaban para subsistir, conservando y manteniendo una serie de prácticas agropecuarias en sus fincas con pocas innovaciones tecnológicas, una forma particular de relación con la tierra en la que la mano de obra familiar es lo más importante y una relación con el entorno, el agua, la biodiversidad que recrea de esta manera una forma de ser propia campesina (Ibíd., 1989).

"El predominio de la pequeña producción de café puede explicarse, en primer lugar, por las condiciones naturales favorables que posibilitan el cultivo del grano y su rentabilidad aún con una mínima inversión de capital. En segundo lugar, porque el cultivo del café, dado el carácter extensivo de las exportaciones y el bajísimo nivel tecnológico correspondiente, demanda gran cantidad de fuerza de trabajo, sobre todo para la cosecha." (Ibíd.: 116).

En las últimas décadas del siglo pasado el capital agroexportador de escala mundial definió nuevas formas de acercamiento y explotación de las formas de producción campesina.

"La región, primero, había soportado una prolongada sequía y luego de un corto período de condiciones climáticas favorables sobrevinieron fuertes inundaciones que determinaron no sólo la pérdida de las cosechas, sino también que las zonas productoras quedasen totalmente incomunicadas. ... muchas unidades de producción fueron parcial o totalmente abandonadas." (Ibíd.: 127).

Los finqueros que durante esa época contrataban mano de obra, vendían el café a buen precio, en los años 90 se vieron obligados a abandonar el campo por las inundaciones provocadas por el fenómeno El Niño, la falta de fuentes de empleo y de ingresos por la caída de los precios de este producto a nivel internacional, unido a las plagas y enfermedades que lo afectaron.

En 1994 se expidió la Ley de Desarrollo Agrario que buscó “modernizar” la agricultura a través de una intervención del Estado por medio de la provisión de servicios de capacitación y crédito para atender a las poblaciones campesinas y afroecuatorianas, "permitió el registro de la propiedad privada de las tierras comunales, la venta de tierras estatales a particulares, así como la libre importación y distribución de insumos y semillas" (Rubio et al., 2008: 25). Así mismo, se da la privatización de las empresas estatales y la liberalización de los precios al consumidor.

En todo el país y específicamente en las áreas rurales de Manabí, la consolidación del modelo neoliberal en la agricultura motivó la disminución de la población rural. La caída de los precios de los cultivos tradicionales de exportación (banano y café); la diversificación hacia otros cultivos como frutales, flores y camarón; la importación de alimentos básicos para la alimentación de la población y el abandono del Estado que se expresa en la inexistencia de políticas para el sector agrícola, falta de control de precios y asistencia técnica, entre otros, dio como resultado el que la producción campesina, especialmente la de maíz, se destine a satisfacer las demandas de las agroindustrias rurales (Ibíd., 2008).

\section{El paso del café a la agricultura intensiva}

Un tema que marca la situación de las familias campesinas en Paján es el cultivo y la cosecha del café. Se crearon organizaciones que adquirieron la forma comunal más de nombre que por su funcionamiento, accedieron a la tierra a través de acuerdos informales, sin mantener una autoridad o formas de acceso a la tierra con carácter comunal, por ello los asentamientos se dan por venta de tierra de manera informal, división de la tierra por crecimiento demográfico y la explotación de los recursos naturales (Guerrero, 2013: 131). 
De ahí que en Paján, por su ubicación y distancia de la capital provincial, las familias campesinas que llegaron a comienzos del siglo anterior, se fueron apropiando de los terrenos en las zonas de montaña, llegaban y desmontaban una parte para sembrar los productos de abastecimiento de la familia, plátano, yuca, fréjol y después empezaban a sembrar café.

\begin{abstract}
"Los primeros ocupantes de la montaña cogían la extensión de tierra que querían, los siguientes tenían que radicarse más adentro o limitar sus aspiraciones, pero también podían comprar muy barato a los primeros la extensión de tierra anhelada que aquella superaba las posibilidades que tenían los pionero de aprovecharla. Desde entonces las posesiones empezaron a dividirse al ritmo progresivamente acelerado del crecimiento poblacional, por entrega a los numerosos herederos más que a los nuevos inmigrantes" (Dubly, 1984: 133).
\end{abstract}

En las pequeñas fincas se podía obtener ingresos importantes durante la cosecha, así mismo a la zona llegaban muchas personas atraídas por los buenos jornales que se pagaban. En los años 60 muchas fincas en Paján se dedicaban fundamentalmente a la producción de café. El café cultivado bajo la sombra de árboles frutales y maderables no necesitaba el uso de insumos químicos ni tampoco dedicación exclusiva, la familia realizaba podas y raleos así como la limpieza del terreno y luego, entre junio y julio y en algunos casos hasta agosto, venía la cosecha, sólo en estos momentos se contrataba la mano de obra, se pedía ayuda a familiares o se recurría al 'presta manos ${ }^{1}$ '. Por ello las familias campesinas podían realizar otras actividades agrícolas y no agrícolas así como criar animales domésticos durante el resto del año.

A tal punto creció la demanda de café, que las fincas que se dedicaban a su cultivo, aumentaron considerablemente así como las plantas que se tenían:

"La presencia de un sinnúmero de fincas que tienen como actividad principal la producción de café determina que Manabí se constituya en el primer productor nacional de café. Para 1968, la provincia concentra el 56.9\% (30.984 fincas) del total de fincas cafetaleras del país (54.426 fincas) y el 56.4\% (106.300 has) de la superficie sembrada con café (188.400 has)," siendo su distribución por zonas así:

- Zona Norte (Bahía de Caráquez, Chone, Calceta y El Carmen): con 60.8 millones de árboles de café, los cuales ocupan una superficie de 40.300 has., equivalente al $38 \%$ de la superficie destinada a la producción cafetalera en Manabí.

- Zona Central (Santa Ana, Portoviejo y Junín): con 16.8 millones de cafetos distribuidos en 19.900 has. (18.8\%).

Zona Sur (Jipijapa, Paján y 24 de Mayo): con una superficie de 45.800 has. (43.2\%) destinada a la producción de café, cuenta con 40.6 millones de cafetos" (Ferrín, 1989: 115).

En la segunda mitad del Siglo XX, primero el café y luego el banano y el camarón tuvieron un importante papel en la actividad primario exportadora del Ecuador. Además de las divisas para el Estado y los ingresos para las familias productoras, comerciantes, transportistas y exportadores, la presencia de café en las fincas permitía el mantenimiento de una diversidad productiva, pues estaba asociado a árboles frutales y forestales y su cultivo no dependía de insumos químicos (Ferrín, 1989).

A fines de los noventa, la crisis de la caficultura por los bajos precios del grano es puesta de manifiesto en numerosos estudios, Chaveau (1999) identifica la crisis de la caficultura en la región Sur de Manabí así:

1 Forma tradicional de reciprocidad en trabajo a la que recurren las familias cuando necesitan mano de obra en las labores agrícolas de preparación de suelo, siembra, cosecha. La familia que recibe la ayuda de familiares y amigos debe retribuir con su trabajo y el de su familia cuando se le requiera.

2 Según la autora "los datos mencionados corresponden a resultados obtenidos en la Primera Encuesta Cafetalera y citados en "El café en el Ecuador" (ROBALINO, 1971). Cabe aclarar que se hace referencia a esta encuesta, por cuanto los resultados del censo cafetalero de 1984 para la época en que se hace el estudio aún no estaban difundidos. 
“... numerosos caficultores con sus familias abandonan completa o parcialmente sus explotaciones agrícolas para ir a vivir a Guayaquil en donde la remuneración del trabajo es mucho más alta. La ruptura del Acuerdo Internacional del Café en 1989, seguida de una caída e inestabilidad de las cotizaciones mundiales, así como las catástrofes climáticas (fenómeno de El Niño en 1997 y 98), han acentuado la dinámica de empobrecimiento en la que se encuentran los caficultores, que ven además desaparecer las oportunidades de trabajo en la ciudad debido a la dramática crisis económica que golpea actualmente al Ecuador" (Ibíd.: 4).

Las familias campesinas que antes recibían la visita de los empleados públicos de los programas estatales del Ministerio de Agricultura y Ganadería o del Ministerio de Bienestar Social, después recibían la visita de los técnicos de las empresas importadoras y comercializadoras de insumos químicos y promotoras del agronegocio como Agripac, Ecuaquímica, India, entre otras.

Las empresas ofrecían a los campesinos lo que se ha dado en llamar un "paquete tecnológico" de maíz y/o arroz que incluía la semilla y los insumos. La oferta hablaba de que se entregaba semilla certificada, algo que los campesinos no tenían, pues estaban acostumbrados a guardar la semilla de una cosecha a otra. Este paquete de insumos para la siembra y control de plagas además incluía el asesoramiento de los técnicos de campo de las mismas casas comerciales.

De esta manera, las agroindustrias vendían sus productos y se aseguraban unos resultados acordes a las condiciones del mercado que ellos controlaban y volúmenes de producto en cada zona. Las familias campesinas por su parte utilizaban su tierra, su mano de obra y asumían los riesgos que demanda la actividad agrícola. Los precios los fijaban fuera de las zonas de producción, en algunos casos con intervención de funcionarios del Estado y a los productores se los castigaba por las condiciones de humedad y calidad del producto.

Los conocimientos campesinos sobre semillas, germinación y rendimiento quedaban de lado para aprender sobre las nuevas "variedades" que llegaban con el paquete químico. Los conocimientos de los regímenes de humedad y de lluvia, el uso del calendario lunar para las labores culturales y el corte de la madera se volvieron obsoletos frente a las instrucciones que venían en los paquetes de semillas e insumos. La posibilidad de que la producción sea comprada por la misma empresa, siempre y cuando se cumpla con las recomendaciones de los técnicos de campo y se siga con rigor las instrucciones en la aplicación del paquete tecnológico, era lo que debía privilegiarse.

\section{Estrategias de resistencia campesina}

Para que la agricultura sea funcional al desarrollo del capitalismo es necesario que esas formas de producción campesina se transformen, lo que implica cambios, reestructuración, adaptación o desaparición según las demandadas del desarrollo capitalista. A consecuencia de ello cada sector de campesinos se maneja de un modo particular, de acuerdo a su proceso de desarrollo histórico.

Las estrategias de vida de las familias campesinas constituyen el conjunto de prácticas y sus diversas combinaciones, que realizan sus miembros basados en la experiencia, para lograr la reproducción global (simple o ampliada) del grupo doméstico. Los procesos de toma de decisiones y construcción de estrategias se estructuran a partir de los deseos, aspiraciones, memoria social, representaciones, modo de vida, y de la particular forma que tienen los sujetos de internalizar los riesgos e incertidumbres a los que se encuentran sometidos en el campo social donde desarrollan sus actividades (Cáceres et al., 2009).

La incidencia de nuevas prácticas productivas, sociales y culturales al interior de las comunidades rurales muestra que las familias campesinas permanentemente están creando nuevas estrategias para hacer frente a los desequilibrios productivos que surgen en el interior de la unidad de producción y a las reglas cambiantes que impone la creciente penetración del capitalismo en las áreas rurales. 
Las estrategias de resistencia de las familias campesinas se construyen alterando y redefiniendo la producción-reproducción y las formas de organización del trabajo dentro del grupo doméstico. Implican distintas prácticas productivas y simbólicas que van desde: prácticas de apropiación y dominio del espacio, prácticas productivas dentro del espacio de dominio, prácticas de movilidad y trabajo extrapredial, prácticas de vinculación (el conjunto de prácticas generadas para la gestación de nuevas unidades domésticas, por ejemplo), hasta prácticas de ayuda personal y de organización comunitaria. Blanca Rubio (2008) las describe como:

\footnotetext{
“Aquellas de corte económico que consisten en fortalecer la producción de autoconsumo como una medida de arraigarse a la tierra, formas de producción agroecológica, la diversificación productiva, la inserción parcial en el mercado, la venta de fuerza de trabajo para complementar el ingreso familiar; hasta la construcción de organizaciones para defender colectivamente sus condiciones productivas" (Rubio et al., 2008: 33).
}

La operación productiva de las familias campesinas se caracteriza por la inestabilidad de los mercados en los que participan, la escasez y/o inexactitud de información técnica apropiada y la inexistencia de mecanismos adecuados de seguridad social. Generalmente las tecnologías supuestamente "mejoradas" han puesto en peligro, y algunas veces, han roto la continuidad productiva de las unidades campesinas. En concordancia, la forma en la que los campesinos enfrentan su actividad productiva, es el resultado de un proceso constante y progresivo entre la satisfacción de sus necesidades básicas y una situación de contexto poco propicia y en permanente cambio.

\section{La diversificación como estrategia}

La crisis de la caficultura marcó la vida de la mayoría de las familias del cantón Paján, individualmente o a través de organizaciones buscaron alternativas para compensar los ingresos que antes les ofrecía el café. Una de ellas fue la de distribuir sus recursos, asignándolos a diferentes actividades productivas, lo que, además de reducir el riesgo y la incertidumbre, permitió apoyar la reproducción social de la familia sobre diferentes fuentes de ingreso.

Las organizaciones que se crearon en Paján y la zona Sur de Manabí con fines productivos y por iniciativa de los proyectos de desarrollo que llegaron a la zona en los años 90, más que con carácter reivindicativo por los temas de tierra o de reivindicación de la identidad o de la organización campesina, incentivaron a las familias campesinas a entrar al cultivo de maíz, de arroz, de ají, como en su tiempo lo hicieron al cultivo de café.

A través de grupos organizados en cada comunidad los proyectos promovieron mejorar la productividad de las fincas, el incremento de la producción, la diversificación productiva, la transferencia de tecnología, en muy pocos casos buscaron transformar la producción agrícola y/o pecuaria en las mismas áreas rurales.

En el 2009, con la recuperación de los precios del café en el mercado internacional algunas de las familias que fueron parte de la investigación en las tres comunidades, volvieron a preocuparse por los cafetales que estaban abandonados. Los cultivos de café que hasta hace unos años no recibían ningún tratamiento, volvieron a ser parte de sus actividades. Se ocuparon de tumbar los viejos cafetales para plantar nuevas variedades de café, hicieron podas, limpieza del terreno, renovaron los árboles que den sombra para así aumentar la productividad.

Atrás de estas iniciativas llegadas desde fuera, las familias campesinas mantuvieron estrategias de diversificación de actividades productivas y de relación con los mercados, que no se apegó al modelo de cultivo único de las zonas maiceras o arroceras de la Costa ecuatoriana y que dan cuenta de procesos de resistencia campesina en la zona de Paján.

Algunas familias de las comunidades de San Francisco, La Trinidad y Mocoral recuperaron las prácticas agrícolas que tenían sus padres y que las personas mayores aún mantenían; 
consiguieron variedades "criollas", especialmente de maíz y arroz que son resistentes a la falta de lluvias de las épocas secas, llegando a tener hasta 30 productos para la alimentación, el mercado y el intercambio con vecinos y familiares que viven fuera.

Una estrategia especialmente importante de las familias campesinas es la diversificación, a la que podemos definir como la forma particular por la cual los campesinos tienden a distribuir sus recursos, asignándolos a diferentes actividades productivas, lo que, además de reducir el riesgo y la incertidumbre, permite apoyar la reproducción social de la familia sobre diferentes fuentes de ingreso. Esta diversificación productiva de las fincas de estas familias de Paján consideraron entre otros los siguientes aspectos:

La tierra, el ordenamiento y uso del espacio: Ordenamiento de la finca de acuerdo a las necesidades de la familia, a las condiciones del terreno y a la disponibilidad de recursos e insumos. Se empieza por el ordenamiento y uso del espacio, en las partes altas y con laderas pronunciadas se resiembra, poda y mejoran los cafetales, los árboles de guaba, laurel y fernán sánchez dan sombra. En las partes bajas se siembra maíz amarillo, habas, habichuelas y yuca. Así mientras se espera el rendimiento del café, se puede ir recogiendo una producción de maíz para alimentación, para los animales e incluso la venta del excedente.

En las partes bajas y de posible inundación se siembra arroz, en los contornos de las parcelas se puede incluir habichuelas, pimiento, tomate, camote. En los terrenos más secos maní, camote. No deben faltar los árboles de papaya, naranja, mango, zapote, guaba, que además de dar sombra y alimento, sus frutos se vende los días de feria en Paján. Si se dispone de más tierra es posible que se deje un espacio con árboles maderables.

Cerca de la casa se instala la era, el sustrato se prepara con "tierra de monte" ${ }^{3}$ que facilita la germinación de las plantas y semillas, se puede utilizar para hacer almácigos o se siembra productos para dar sabor a la comida: cilantro, cebolla, orégano, oreganito, pimiento, tomate; y, plantas aromáticas: yerba luisa, ruda, menta, congona, entre otras.

Cerca de la casa está el espacio para los animales, el "chiquero de los puercos", el árbol donde duermen las gallinas, el sitio de pavos y patos que se crían y se alimentan con los restos de la cosecha: cáscaras y tallos de plátano, granos de maíz, cáscaras de yuca así como con los restos de comida; un poco más alejado el corral si es que hay ganado. De esta manera se facilitan las tareas de alimentación e hidratación, y se cuidan en caso de que personas extrañas lleguen a robar durante las noches.

La diversificación pecuaria, agrícola y forestal: En manejo simultáneo de sistemas agrícolas, pecuarios y forestales, y con la mayor diversificación de especies en cada uno de ellos, está de acuerdo a las posibilidades de mano de obra, tierra y dinero. Los productos que se siembran sirven para la alimentación de la familia, para criar animales que a su vez sirven también para alimento y obtención de ingresos y mientras estos crecen, los árboles maderables y frutales van dando sombra y más adelante sus frutos.

Subyace en este planteamiento la disponibilidad de obtener alimentos para la subsistencia de la familia durante todos los meses del año; disminuir la dependencia y riesgos de un solo producto; obtener ingresos permanentes para los gastos de educación, salud, vestimenta; y, la interrelación de cada uno de ellos.

EI manejo de la fertilidad: El reconocimiento y valoración de los productos de la zona no sólo tienen que ver con el mantenimiento de las tradiciones, subyace un conocimiento de manejo de fertilidad y de vocación de los suelos. El corte de la maleza con el machete y el garabato ${ }^{4}$ permite que los trabajadores puedan identificar las plantas benéficas de las "malas hierbas", actividad que es imposible si se utiliza el paquete químico pues acaba con todo lo

3 Tierra con abundante hojarasca en descomposición que se la puede recoger entre los cafetales, tiene alto contenido de materia orgánica y es apta para el crecimiento de los cultivos.

4 Pedazo de madera en forma de "l" que se lo toma con la mano izquierda y facilita el agarre de la maleza que se corta con el machete. 
que crece junto a las plantas. La costumbre de quemar el rastrojo y hacer "lagarteras", además de controlar la maleza, la ceniza evita que los insectos se coman la semilla y "espanta" o aleja a las culebras.

Con la reactivación de la caficultura, en talleres y días de campo se enseña a preparar insumos (bioles, humus) para ayudar en la fertilidad de los suelos, aprovechando las plantas que crecen en el medio (zaragoza, ají, nin), y comprando otras (ajo, cebolla).

El uso de semillas: Las estrategias de diversificación de las familias campesinas de Paján no serían posibles si no se hiciera una valoración y recuperación de las semillas tradicionales. Las variedades locales de semillas tienen la ventaja de que están adaptadas a las condiciones de suelo, humedad y altitud.

Conocer y manejar cada una de las semillas es fundamental para el trabajo en las fincas. Hay múltiples formas de almacenar, diferentes lugares y recipientes que se utilizan para alejar a roedores e insectos.

Los insumos externos: En el maíz y el arroz se utiliza un paquete de productos químicos en cambio el café necesita pocos insumos externos. La combinación de insumos locales y el paquete de químicos garantizan la inversión realizada.

El agua y la recuperación / manejo de la humedad: Siendo Manabí una zona con escasez de agua, la recuperación y manejo de la humedad se convierte en un tema fundamental en las labores agrícolas, los períodos de sequía o de lluvia abundante se suceden de forma cíclica. Las familias buscan fuentes de agua, esteros o ríos en donde hacen tapes o albarradas.

El trabajo familiar: Las familias campesinas incluyen a todos sus miembros en el trabajo agrícola, inclusive los niños luego de asistir a la escuela ayudan en las tareas más fáciles de la casa y del campo como parte de su proceso de socialización y de aprendizaje. Aunque algunas mujeres se quedan en la casa y los hombres van al campo, en otras las mujeres realizan todas las actividades por igual. En los momentos de más demanda en las labores culturales, siembra y limpieza del terreno, pueden recurrir a la contratación de jornaleros, o se dan la mano (cambia manos o presta manos).

Las decisiones y estrategias adoptadas durante el año responden a un conocimiento profundo de las condiciones del medio, de los productos y de lo que deben hacer para lograr el sostenimiento de la familia.

La comercialización: Aunque se prioriza el autoconsumo como parte de la reproducción de la unidad doméstica, a la obtención de ingresos se destina una parte importante del trabajo y de los productos de la finca. Los productos que salen de las fincas se venden en Paján a los intermediarios, ellos son los que imponen los precios y las condiciones en las que debe presentarse el producto, siendo una parte muy sensible es la que menos controlan las familias pues dependen de los precios del mercado, de las condiciones para llevar los productos, por ello algunos prefieren vender en finca aunque les paguen menos.

La venta de mocora ${ }^{6}$, de tagua, la elaboración de artesanías, la venta de mano de obra en la construcción o en la agricultura complementan los ingresos familiares.

Los arreglos para producir: Las relaciones con vecinos, compadres y familia son importantes para realizar las labores agrícolas, son ellos los que ayudan con el trabajo, prestan animales o dinero. Obtener crédito es muy difícil por la falta de legalización de los terrenos, las casas comerciales y programas estatales entregan semillas con el paquete de insumos necesarios para el cultivo de maíz y café. Entre los requisitos exigidos estaban el formar un grupo, participar en las actividades de capacitación y organizar el trabajo en cada finca.

5 Una vez separados los troncos grandes para leña en el terreno se dejan filas de maleza separadas cada dos metros para hacer una quema controlada.

6 La mocora o Astrocaryum Standleyanum crecía de manera silvestre en los pequeños bosques de Paján, ahora se buscan los brotes que crecen espontáneamente para poder sembrar. Se cortan los brotes nuevos que son los que se utilizan para extraer el nervio principal que es de donde se saca la fibra. Luego de secarla al sol se la vende a intermediarios que la llevan a Perú. 


\begin{tabular}{|c|c|c|}
\hline Mes & Actividad & Descripción \\
\hline Enero & $\begin{array}{l}\text { Se prepara el terreno para } \\
\text { las siembras. Esto incluye } \\
\text { limpiar las malezas y } \\
\text { quemar el rastrojo en } \\
\text { lagarteras. }\end{array}$ & $\begin{array}{l}\text { Aprovechando las primeras lluvias del invierno, "ganan } \\
\text { manos para la siembra", es decir que con mis padres y } \\
\text { hermanos vamos un día a un terreno y otro día a otro. }\end{array}$ \\
\hline Febrero & $\begin{array}{l}\text { Se siembra yuca y } \\
\text { plátano, arroz, maíz y } \\
\text { maní. }\end{array}$ & $\begin{array}{l}\text { Elementos importantes en la alimentación familiar que } \\
\text { permite preparar una serie de alimentos tradicionales y } \\
\text { vender en el mercado local. }\end{array}$ \\
\hline Marzo & $\begin{array}{l}\text { Se prepara el terreno } \\
\text { para la siembra de café. } \\
\text { Se hace la limpieza del } \\
\text { arroz, maíz y maní. } \\
\end{array}$ & Como es una actividad muy difícil, se contrata trabajadores. \\
\hline Abril & Se siembra el café. & $\begin{array}{l}\text { Las labores agrícolas disminuyen pues es el tiempo de } \\
\text { matrícula e inicio del año escolar de los niños y jóvenes. }\end{array}$ \\
\hline Mayo & Cosecha de arroz. & $\begin{array}{l}\text { Labor de cortar, acarrear, apilonar y chicotear la panca de } \\
\text { arroz, el grano obtenido es secado de forma natural, con } \\
\text { dos fines, pilar de inmediato para el consumo/venta, otra } \\
\text { parte se guarda para semilla y el excedente se consume } \\
\text { paulatinamente durante el resto del año. }\end{array}$ \\
\hline Junio & $\begin{array}{l}\text { Cosecha de maní y maíz. } \\
\text { Se trabaja el café. }\end{array}$ & $\begin{array}{l}\text { Como recién se ha sembrado el café, se debe limpiar el } \\
\text { monte para que no le gane a crecer la maleza que impide su } \\
\text { desarrollo. }\end{array}$ \\
\hline Julio & $\begin{array}{l}\text { Se hace el mantenimiento } \\
\text { al café. Se asolea el arroz. }\end{array}$ & $\begin{array}{l}\text { Limpiar las malezas para que esté listo para la cosecha. } \\
\text { El arroz guardado se asolea nuevamente para ser pilado }\end{array}$ \\
\hline Agosto & Se recoge el café. & $\begin{array}{l}\text { Se guarda la semilla para el invierno, se separa lo que se } \\
\text { utilizará en la casa o para regalar y lo que se vende. }\end{array}$ \\
\hline Septiembre & Se saca la paja mocora. & $\begin{array}{l}\text { El trabajo en los cultivos disminuye, se recoge y limpia la } \\
\text { paja mocora para la venta lo que permite el sustento diario. }\end{array}$ \\
\hline Octubre & $\begin{array}{l}\text { Se vende la paja mocora. } \\
\text { Se cosecha la naranja. }\end{array}$ & Luego de secada, se lleva la paja al mercado. \\
\hline Noviembre & $\begin{array}{l}\text { Se hace el vivero de café. } \\
\text { Se busca tierra de guaba. } \\
\text { Se busca leña para el } \\
\text { invierno. }\end{array}$ & $\begin{array}{l}\text { La hojarasca que cae del árbol de guaba, más arena es el } \\
\text { sustrato que se utiliza para llenar las fundas de plántulas de } \\
\text { café en el vivero que luego serán trasplantadas al terreno. } \\
\text { La leña es un elemento indispensable para preparar la comida } \\
\text { típica: torta de plátano, torta de choclo, bollos, los muchines } \\
\text { de verde (plátano verde) o de yuca, la carne asada, el plátano, } \\
\text { yuca o maduro asado como acompañantes de la comida. }\end{array}$ \\
\hline Diciembre & $\begin{array}{l}\text { Se buscan las vegas que } \\
\text { se utilizarán para sembrar } \\
\text { en el invierno. } \\
\text { Se riega los semilleros } \\
\text { de café. } \\
\text { Se cosecha mango. }\end{array}$ & $\begin{array}{l}\text { Es el mes en el que se prepara y planifica el nuevo } \\
\text { ciclo agrícola. Como todavía no llueve se deben regar } \\
\text { manualmente los semilleros de café. }\end{array}$ \\
\hline
\end{tabular}

Fuente: C. Sánchez, entrevista, 2013. Elaboración propia. 


\section{Conclusiones}

El café no solo definió un momento importante de llegada de las familias campesinas a la zona sino que está presente en la historia de las comunidades del cantón Paján. Su época de bonanza y su caída marcaron la vida de la población, las condiciones de fertilidad y disponibilidad de tierra permitió que se quedaran. En los años de la caída de los precios fue la causa para que las familias campesinas opten por migrar a las áreas urbanas.

La caída de los precios del café a fines de los ochenta que coincidió con condiciones climáticas adversas y la presencia de plagas y enfermedades provocaron la baja en la producción y el abandono de los cafetales. No todas las familias pudieron resistir y tuvieron que abandonar sus fincas para ir a las ciudades. En la actualidad el café representa parte de una estrategia de resistencia combinado con una producción diversificada.

Las estrategias de resistencia de las familias campesinas en Paján, que más que oponerse y organizarse para resistir al modelo de monocultivo y alto consumo de insumos químicos, tienen que ver más bien con la posibilidad de encontrar formas de organización del trabajo y formas de producción y reproducción de las unidades domésticas en las que está presente la diversificación.

Aunque no todas las familias lo hacen, documentar este tipo de experiencias dentro de un enfoque antropológico en el que se integra aspectos de la cultura campesina y montubia de las áreas rurales de la provincia de Manabí, da cuenta de la multiplicidad de estrategias que adoptan las familias campesinas para, en el siglo XXI, mantenerse en el campo. 


\section{Bibliografía}

Chauveau, Christophe. 1999, La crisis de la caficultura del cantón Jipijapa. Diagnóstico agro-económico de una vieja región cafetalera de la Costa ecuatoriana, VECO, Ecuador.

Dubly, Alain. 1984, La situación de los campesinos en ocho zonas del Ecuador. Tomo 1., ALOP, CESA, CONADE, FAO, MAG, SEDRI, Quito.

Dueñas de Anhalzer, Carmen. 1986, Historia económica y social del norte de Manabí, Ediciones Abya Yala, Quito.

Dueñas de Anhalzer, Carmen. 1991, Soberanía e insurrección en Manabí, Abya-Yala, FLACSO, Quito.

1987, Movimientos políticos en la provincia de Manabi durante la segunda mitad del Siglo XIX, Tesis de Maestría en Historia Andina, FLACSO, Quito.

Ferrín, Rosa. 1989, "Situación y perspectiva de la producción cafetalera en Manabí, en: La investigación económica en el Ecuador, ILDIS, Quito, pp.:109-137.

Guerrero Cazar, Fernando. 2013, "Proceso organizativo del campesinado en el sur de Manabí y desarrollo rural", en: Íconos. Revista de Ciencias Sociales, FLACSO- Ecuador. No. 45. Enero, Quito, pp.: 127-140.

Instituto Nacional de Estadísticas y Censos. www.inec.gob.ec

2014, Censo de Población y Vivienda 2010. Cantón Paján.

Plúas Villarroel, Erika Lisbeth. 2011, Análisis Económico: Producción de Café en el Cantón Paján 2008-2010, Tesis para optar por el Título de Economista. Universidad De Guayaquil. Facultad de Ciencias Económicas. Diciembre 2011, Ecuador.

Rubio, Blanca et al. 2008, Formas de explotación y condiciones de reproducción de las economías campesinas, Ediciones La Tierra, Quito.

Sistema Nacional de Información. http://sni.gob.ec 